\title{
Transportation disadvantage impedance indexing: A methodological approach to reduce policy shortcomings
}

\author{
Yavuz Duvarci $^{\mathrm{a}}$, Tan Yigitcanlar ${ }^{\mathrm{b}, *}$, Shoshi Mizokami ${ }^{\mathrm{c}}$ \\ a Department of City and Regional Planning, Izmir Institute of Technology, Gülbahce, Urla, Izmir, Turkey \\ b School of Civil Engineering and Built Environment, Queensland University of Technology, 2 George Street, Brisbane, QLD 4001, Australia \\ c Civil and Environmental Engineering, Kumamoto University, 2-39-1 Kurokami, 860-8555 Kumamoto, Japan
}

\section{A R T I C L E I N F O}

\section{Article history:}

Received 25 November 2014

Received in revised form 3 June 2015

Accepted 18 August 2015

Available online 1 September 2015

\section{Keywords:}

Transportation disadvantaged

Social exclusion

Transportation disadvantage-impedance index Policymaking

Simulation modelling

Arao, Japan

\begin{abstract}
A B S T R A C T
Access to transport systems and the connection to such systems provided to essential economic and social activities are critical to determine households' transportation disadvantage levels. In spite of the developments in better identifying transportation disadvantaged groups, the lack of effective policies resulted in the continuum of the issue as a significant problem. This paper undertakes a pilot case investigation as test bed for a new approach developed to reduce transportation policy shortcomings. The approach, 'disadvantage-impedance index', aims to ease transportation disadvantages by employing representative parameters to measure the differences between policy alternatives run in a simulation environment. Implemented in the Japanese town of Arao, the index uses trip-making behaviour and resident stated preference data. The results of the index reveal that even a slight improvement in accessibility and travel quality indicators makes a significant difference in easing disadvantages. The index, integrated into a four-step model, proves to be highly robust and useful in terms of quick diagnosis in capturing effective actions, and developing potentially efficient policies.
\end{abstract}

(c) 2015 Elsevier Ltd. All rights reserved.

\section{Introduction}

The research conducted over the last decades resulted in identifying the major problems and locations of socially excluded (in broad terms, people with the lack of participation in the economic, political and social life of the community) and transportation disadvantaged (TDA) (in broad terms, people that are prevented from participation in the economic, political and social life of the community because of the reduced accessibility to opportunities, services and social networks) groups (Litman, 1997; Schlossberg, 2004; Duvarci and Yigitcanlar, 2007; Delbosc and Currie, 2011a; Blair et al., 2013; Kamruzzaman et al., 2015; Rashid and Yigitcanlar, 2015; Schwanen et al., 2015). As a result, many cities around the globe develop policies in order to meet the needs of these groups (Battellino, 2009). Utility of new technologies and high capacity computers are seen as support tools in these policymaking efforts (Yigitcanlar et al., 2010). However, estimating the effectiveness of policies beforehand is immensely critical, where this can be achieved by implementing cost-effective simulations using transportation models (Kamruzzaman and Hine, 2011; Kamruzzaman et al., 2014). Yet, up-todate travel demand model software packages have neglected to incorporate social considerations and the required equity parameters, even

\footnotetext{
* Corresponding author.

E-mail addresses: yavuzduvarci@iyte.edu.tr (Y. Duvarci), tan.yigitcanlar@qut.edu.au (T. Yigitcanlar), smizo@gpo.kumamoto-u.ac.jp (S. Mizokami).
}

for the neediest-i.e., disabled and elderly (Banister, 2002; Delbosc and Currie, 2011b; Lucas, 2012; Wasfi et al., 2012).

Furthermore, as emphasised by Lucas $(2012,112)$, "if properly designed and delivered, public transport can provide a part of [the TDA] solution, but it is most likely that other forms of more flexible (and often informal) transport services will be needed to complement these mainstream services. [Nonetheless,] this does not come cheap." Consequently, insufficient funds, high costs of special treatment of TDA, and costly provision of the special services enforce policymakers to look for cost-effective, timesaving, appropriate, and applicable solutions (Metz, 2003). Simulation models provide opportunity to test policy effectiveness before their implementation (Barceló, 2010); however, at present there are no straightforward policy simulation applications in the TDA domain.

The primary aim of this research is to develop an indexing approach, 'disadvantage-impedance index (DIX)', to fill this gap. Travel 'impedance' to the nearest service, in distance or time, is a commonly used measure of spatial accessibility (see McGrail and Humphreys, 2009). The term is also used to refer to transport related disadvantageous situations travellers experience such as very long walking distances to/from public transport stops or poor quality of public transport system (see Bunker et al., 2015). DIX is developed through the adjustment of modelling routine, as existing software are restricted in effective policymaking due to neglected social considerations. This indexing approach enables obtaining the best policy measures requiring only single-shot collected data in utilised cyclic run iterations. In DIX, stated 
preference data technique (P.data) is used to obtain detailed information from the population, for better and quicker policy capturing, instead of blind trials for finding best policies. This approach aims to provide a solution to represent TDA views in policy determination. Therefore, it utilises mixed stated preference and revealed preference survey techniques, to understand traveller reactions against various policy scenarios, and helps inclusion of the user preferences, and thus enables participation of TDA in the policymaking process containing different scenarios and solution options (Lam and Xie, 2002; Alver and Mizokami, 2006; Duvarci and Mizokami, 2009). Investigating the compatibility of the approach to commercially available mainstream software-i.e., JICA-STRADA-is the secondary aim of this research.

\section{Literature review}

The common characteristics of disadvantaged populations are extensively discussed in the literature-see Church et al. (2000), Hine and Grieco (2003), Hine and Mitchell (2003), Duvarci and Yigitcanlar (2007), and Duvarci et al. (2011). While mostly used interchangeably, TDA and transport-related social exclusion are not necessarily synonymous with each other. For instance, a socially excluded can have good access to public transport options or a transport disadvantaged can be socially included (see Stanley and Vella-Brodrick, 2009; Delbosc and Currie, 2010). According to Lucas $(2012,106)$ "rather [TDA] and social disadvantage interact directly and indirectly to cause transport poverty. This in turn leads to inaccessibility to essential goods and services, as well as 'lock-out' from planning and decision-making processes, which can result in social exclusion outcomes and further social and transport inequalities will then ensue". Not only personal and socioeconomic reasons (Licaj et al., 2012), but also the transport system itself can have a crucial role in creating barriers (Church et al., 2000). Hine and Grieco (2003) argue that combination of poor accessibility with low levels of mobility, and low levels of sociability intensifies the social exclusion. According to Lucas (2006) among the TDA categories, the elderly and disabled deserve more attention.

Many countries-i.e., Sweden, Canada, and Australia-have already launched legislations requiring improvements in transportation services such that all members of the society have equity in accessibility and mobility (Currie et al., 2009; Dodson et al., 2010; Engels and Liu, 2011; Jones, 2011). France, Spain, Canada, New Zealand, and South Africa are responding to the TDA agenda, and without directly calling it TDA policy, the USA, Germany and the Netherlands offer policies to address the transport needs of disadvantaged groups (Lucas, 2012). The success factors are among the most popular issues for effective policy solutions for TDA groups (Rau and Vega, 2012). Developing special infrastructure (e.g., technology equipped special services) for aiding TDA groups (especially disabled and elderly) is needed; however, it brings additional cost to local authorities, which is a major obstacle in implementation (Mokhtarian et al., 2006). Developing appropriate policies with support of technology is a much more cost-effective method in aiding those vulnerable groups (Nicolle and Peters, 1999; Duvarci and Mizokami, 2007; Yigitcanlar and Kamruzzaman, 2014), which requires detailed information such as travel demands, preferences, modes and paths of the population.

Gaining information about the TDA groups is necessary to identify and document their accessibility and mobility needs (Lucas, 2011; Power, 2012), which can be suitably acquired through four-step travel demand modelling. The importance of planning integrated to travel demand models has been ignored in the contemporary efforts due to unawareness and lack of coordination between social institutions, including health and transportation service authorities. Nevertheless, the ability to configure proper policy measures to help improve the TDA is of prime importance for policymakers to lessen the avoidable costs for both operators and users (Diana, 2004).

Measurement and level of analysis difficulties arise in TDA studies due to the multi-dimensionality of TDA. However, in some of the TDA studies (Duvarci and Yigitcanlar, 2007; Duvarci et al., 2011), these methodological issues were addressed by using P.data. This helped in determining the degree of disadvantages in social and geographical terms. There is a need for developing a clear methodological approach to determine appropriate policies to decrease disadvantages-making TDA people equal or close to non-TDA (NTDA) population in terms of their travel characteristics and opportunities. However, while providing solution to TDA problem, it carries the risk of increased demand on the road network causing congestion. Fortunately, a simulation study (Duvarci and Mizokami, 2007) reveals that even in the case of removal of all disadvantages, releasing suppressed trips of TDA would not cause a burden on existing road infrastructures.

\section{The disadvantage-impedance indexing approach}

The disadvantage-impedance Index (DIX) is developed with an aim to compare available policies to improve TDA's travel conditions and test effectiveness of these policies in a simulation environment. The structure and cycling process of the indexing approach are shown in Fig. 1. The data used in the index is clustered as TDA and NTDA. Information from P.data, fed by the current ( $t$ time) clustering results of TDA, guides the choice of appropriate policy areas to focus on. Convinced that improvements through simulations (both in terms of significantly easing the disadvantages and network congestion) are satisfactory to reduce the gap between TDA and NTDA, indicator index values are converted to composite index values (DIX) and should be treated for observing new cluster analysis $(t+1$ time) results. This is to test whether the TDA population changed and the gap (cluster centre results) is further reduced. The process stops, if the goal is achieved, and the best solution scenario is nominated. Only the changing P.data values-along with TDA profile improvements at each cycle-are applied to the same modelling values.

The clustering process of the index is a dynamic one, and its results are expected to change (improvement for TDA) after each iteration cycle. Hence, the index always uses the same data in normalised index values for convenience of input-output cycle operability, and for reducing complexity. As stated by Parumog et al. (2008) using the improvement ratios as the common measurement between non-comparable indicators is a suitable technique for normalisation of values. In the light of the new TDA evaluation routine-using cluster analysis, P.data, input of DIX indicators-improvements in the travel demand modelling structure of a commercial transport modelling software (i.e., JICASTRADA) are elaborated as below.

Improvements made through simulations in the original zonal DIX are achieved by: (i) Obtaining the improvement rates by zones and indicators, and; (ii) converting the improvements into averaged rate values by zones to be added to the respected indicator index values. The ratio change of TDA out of total population, as a result of the next clustering cycle, is a concern for evaluating performance of the system. This ratio change would not be a sole evaluator when the ratio of TDA can get even larger than the previous case, if its conditions are improved because of the increased numbers of TDA getting closer to NTDA. Thus, the metric gauge used for the improvement should be the reduced gap between overall cluster centre values of the two populations (increase in the TDA's cluster centre value) instead of the number of TDA people. Cluster centre values of each indicator for each zone can be used as a gauge to measure the improvement. If cluster centre values of TDA and NTDA converge to a negligible difference (5\%), the process and the search for equalisation of TDA to NTDA should be stopped, and the finalised simulation results should be reviewed for policy analysis. The Pareto optimality condition is reserved such that any increase in DIX can only rise up to that of NTDA; if exceeded, imbalance of disadvantage would be borne, avoiding equity. The way to sort out the best policies within this mechanism is beyond the scope of this paper. 




Fig.1. Structure and cyclic process of the disadvantage-impedance indexing approach.

\section{Methodology of the approach}

\subsection{Indicator base}

The approach has two types of indicators-composite and individual indicators. Indicators are selected as a result of the following considerations: (i) Lead of the literature; (ii) use of indicators practically as both input and output-meaning that data is recycled and altered from one iteration cycle to another to be used as an input for the next simulation round. This approach is followed mainly due to inconvenience of frequent data collection from the field; (iii) indicator values to explain the reasons behind being of disadvantaged-for instance, disability should not be considered as a TDA factor, if the transportation system is adequate in accommodating them appropriately, and; (iv) compatibility with commercial travel demand software-i.e., JICASTRADA.

The approach contains five composite indicators-i.e., accessibility (Access), land use and environmental conditions (LandEnv), physical barriers (PhysBarr), travel quality and comfort (TravQual), and transport system satisfaction and bus-stop conditions (TrSysQual). For each composite indicator a number of individual indicators are assigned-a total of 30 indicators (Table 1). These composite and individual indicators correspond to the most basic and essential elements of TDA and are driven from the key literature (e.g., Ewing et al., 1996; Thompson, 2001; Duvarci and Yigitcanlar, 2007; Yigitcanlar et al., 2007; Loader and Stanley, 2009; Currie et al., 2010; Delbosc and Currie, 2011b, 2011c; Kamruzzaman and Hine, 2012; Schwanen et al., 2015). As accessibility plays a significant role in a person's TDA status, in this approach, accessibility to transport is, with some nuances, placed under the composite indicators of 'TravQual' (distance to the nearest public transport stop) and 'TrSysQual'(distance to available public transport modes) rather than 'Access'. The indicator structure of the DIX is presented in Table 3. Data required for these indicators are collected through a household travel survey. Appendix 1 presents the survey questionnaire.

In obtaining recyclable data values across all indicators, normalisation plays a central role that is conveniently realised by standardisation of all non-categorical data to adjust their values measured on different scales to a notionally common scale. For the normalisation technique Min-Max-Scaling is used as a means that one linearly transforms real data values such that the minimum and maximum of the transformed data to take certain values between 0 and 100 . The main reason of choosing this technique over others (e.g., z-score that normalises based on the mean; or decimal scaling that normalises by moving the decimal point of values) is that Min-Max-Scaling preserves the relationships among the original data values. For categorical data, normalisation of all index indicator values to a five-scale system (i.e., lowest, low, 
Table 1

Disadvantage indicators.

\begin{tabular}{|c|c|}
\hline Composite indicators & Individual indicators \\
\hline Accessibility (Access) & $\begin{array}{l}\text { - Distances to work place or school, } \\
\text { - Distances to hospital and medical centre. } \\
\text { - Distances to shopping centre and corner or } \\
\text { convenience store. } \\
\text { - Distances to park and recreational activities. } \\
\text { - Distances to social, cultural and religious activity } \\
\text { centres. } \\
\text { - Distances to nearest public transport stop from } \\
\text { home-distance as an aggregate value/measure } \\
\text { for individuals' accessibility levels. } \\
\text { - Distances to nearest public transport stop from } \\
\text { work or school-distance as an aggregate } \\
\text { value/measure for individuals' accessibility } \\
\text { levels. }\end{array}$ \\
\hline $\begin{array}{l}\text { Land use and environmental } \\
\text { conditions (LandEnv) }\end{array}$ & $\begin{array}{l}\text { - Convenience of the residential neighbourhood for } \\
\text { - Convenience of the employment area for travel } \\
\text { to home and all other land use destinations. } \\
\text { - Offering of the residential neighbourhood for } \\
\text { active transport-walkways and bikeways. } \\
\text { - Frequent use of active transport } \\
\text { infrastructure-walkways and bikeways. } \\
\text { - Safety and security of the residential } \\
\text { neighbourhood's streets-effectiveness of street } \\
\text { lightings at nights. } \\
\text { - Density and traffic load of the residential } \\
\text { neighbourhood-urban density and bypassing } \\
\text { traffic and congestion levels. }\end{array}$ \\
\hline Physical barriers (PhysBarr) & $\begin{array}{l}\text { - Steep slopes-slope angle of } 20 \% \text { or greater for a } \\
\text { minimum of } 10 \text { m horizontally. } \\
\text { - Narrowness of roads. } \\
\text { - Lack of footpaths and dedicated walk paths. } \\
\text { - Difficulty in driving-due to road surface and traf- } \\
\text { fic conditions. } \\
\text { - Not an ideal footpath condition-no consideration } \\
\text { in the design for disabled people and parents with } \\
\text { prams/strollers, such as non-dropped kerbs, } \\
\text { width of the footpaths and absence of natural or } \\
\text { built protection elements from weather condi- } \\
\text { tions. } \\
\text { - Traffic lights and long waiting times at crossings. } \\
\text { - Insufficient traffic and road condition information } \\
\text { and signs. }\end{array}$ \\
\hline $\begin{array}{l}\text { Travel quality and comfort } \\
\text { (TravQual) }\end{array}$ & $\begin{array}{l}\text { - Distance to the nearest public transport } \\
\text { stop-distance as a perceived value/measure } \\
\text { for individuals' accessibility levels impacting } \\
\text { their views on travel quality. } \\
\text { - Travel time, total travel cost per travel. } \\
\text { - Number of transfers ever made during travel. } \\
\text { - Distance to the destination from car park or } \\
\text { public transport stop-distance as a perceived } \\
\text { value/measure for individuals' accessibility } \\
\text { levels. } \\
\text { - General evaluation of travel quality and } \\
\text { satisfaction-as a parameter to measure physical } \\
\text { conditions of public transport travel and vehicle } \\
\text { quality perceived by individuals. }\end{array}$ \\
\hline $\begin{array}{l}\text { Transport system satisfaction } \\
\text { and bus-stop conditions } \\
\text { (TrSysQual) }\end{array}$ & $\begin{array}{l}\text { - Distance to available public transport } \\
\text { modes-distance as a perceived value/measure } \\
\text { for individuals' accessibility levels impacting } \\
\text { their views on transport system quality. } \\
\text { - Availability of other public transport modes. } \\
\text { - Physical conditions of public transport stops. } \\
\text { - Reliability and frequency of the public transport } \\
\text { system. } \\
\text { - Seat availability and comfort in the public transport } \\
\text { system. }\end{array}$ \\
\hline
\end{tabular}

medium, high, highest) is executed as follows: The lowest value is the median value of the Lowest range, 5, and the Highest value is 95 (neither 0 nor 100 is assigned). Other values are assigned as for: Lower value (scale interval 20-40) 30; Middle value (40-60) 50, and;
High value (60-80) 70. The conversion function for the noncategorical data uses the Min-Max-Scaling equation given below:

$x_{i}=\frac{\left(x-x_{\min }\right)}{\left(x_{\min }-x_{\max }\right)}$

where $x_{\mathrm{i}}$ is the new normalised ratio value, $x$ is any data value to be normalised, and, $x_{\min }$ and $x_{\max }$ are the minimum and maximum values in the data set of the specific indicator.

Following the normalisation process, standardised data is used for value calculation for all five composite indicators. Once the composite indicator value is calculated for households, the value is reflected on each of the household members-individuals. Upward values (approaching to 1) indicate positive utility and thus those people are lower level or no disadvantage, and naturally downward values (approaching to 0) indicate higher-level disadvantage. For instance, composite indicator value for 'LandEnv' is calculated as follows:

LandEnv $v_{i j}^{n}=\sum_{m=1}^{n} w_{m} x_{m} \quad$ for $\forall m \in n$

where LandEn $_{\mathrm{ij}}$ represents the land use and environmental conditions, where $i$ and $j$ indicate the surveyed people and zone respectively, $x$ is the $m^{\text {th }}$ indicator's normalised value, and $w_{m}$ indicates the assigned weight value of the $m^{\text {th }}$ indicator gathered from the surveyed people.

Calculation of weightings $\left(w_{n}\right)$ of the individual indicators of the LandEnv composite indicator is undertaken through the rank ordering method of the survey participants' responses. Consequently, when there are $n$ (for this composite indicator, six) indicators (which are corresponding to six questionnaire items) of the LandEnv indicator, the total points a person receives are calculated with the formula given below.

$\operatorname{LandEnv}_{i j}^{n}=\frac{\sum_{m=1}^{n}\left(w^{1} \operatorname{LandEnv}_{i j}^{1}+w^{2} \operatorname{LandEn}_{i j}^{2}+. .+w^{n} \operatorname{LandEn}_{i j}^{n}\right)}{n}$

\subsection{Index calculation}

The index value (DIX) is the summative combination of all five composite indicator values to a single overall indicator, where zonal DIX (zDIX) is the mean average value for a zone-the aggregation is undertaken through taking the average value of all surveyed persons in a specific zone. We assume that all five composite indicators share the same importance, thus an equal weight is assigned, as they are representing equally important but different realms impacting disadvantage levels. The calculation of the index is done as below:

$\mathrm{DIX}=(0.2 a+0.2 b+0.2 c+0.2 d+0.2 e)$

where $a, b, c, d$ and $e$ are composite indicators calculated by using Eq. (3). The value of 0.2 is the equal weight coefficient assigned to each of the composite indicator.

Since the proposed modelling structure is zone-based, all personbased normalised values are converted to zone aggregate values following the clustering process (i.e., after each iteration). Index values are calculated for each trip purposes-i.e., work, all other, and return-in order to detect disadvantages for each trip purposes, as one person disadvantaged for one trip purpose may not be for another.

Total Zonal Disadvantage Impedance Index (tzDIX) is a cyclic disadvantage calculation method including both zDIX and 'time and cost impedance' (TCI). DIX and zDIX only measures the TDA level focussing on the sources of disadvantages. Including TCI in tzDIX measures makes changes between the new situation $(t)$ and 
the previous case $(t-1)$. The reason for insertion of all population's $\mathrm{TCI}$ in the measurement system is that inclusion of all generalised costs is borne by the increase in TDA's travels. The travel demand software utilising OD matrices calculates the TCI impedance easily. Nevertheless a separate calculation for TDA and NTDA is not possible as both comprise non-separable traffic on a network. Disadvantage indicator impacts can be measured only after observing simulation applications as model outputs. zDIX, however, is pre-determined from P.data as a probability of conditions. In Eq. (5), zDIXs are placed at the left hand side and the trip impacts (usually cost as TCI) are at the right hand side of the impact calculation. Since trip rate increase and modal shift to public transport mode are perceived as positive contributions, these impacts are not included in the disadvantage impedance calculation. Evidently, most of the time TCI change has a negative sign when improvements were made in the zDIX side, together with supposedly increased trip rates, causing more congestion and delays in the system as a price of the improvement and decreased 'level of service' (LOS). Thus, extra traffic load can have a negative impact (such as congestion) on the TDA's situation, and should be subtracted from the improvement (positive side) of the zDIX, when trip rate or travel time increases.

$t z D I X_{t}=\left(z D I X_{t}+(-\Delta \mathrm{TCI})\right)=\left(z D I X_{t}-\Delta T C I\right)$

where $\Delta$ represents the difference between the $t$ and $t-1$ times in policy scenarios. Only the initial tzDIX does not contain TCI component as there is no result of $z D I X$ impact at this stage.

Since the tzDIX calculations are origin-based, all origins' impedance changes (from $t-1$ to $t$ time) to all destinations to be aggregated and average changes to be taken into account as shown in the following equation:

$T C I_{i}=\frac{\sum_{j}\left(I_{i j}\right)}{Z_{j}}$

where $Z_{\mathrm{j}}$ is the total number of destination zones, $j$ indicates all destinations and $I$ is the classical TCI impedance difference.

\subsection{Clustering process}

In this study, simple K-means type clustering technique is used in the cyclic modelling for improving the simulation results. K-means is a technique that partitions observations into $\mathrm{K}$ clusters in which each observation belongs to the cluster with the nearest mean and thus serving as a prototype of the cluster. This clustering technique requires definition of $\mathrm{K}$ numbers of clusters from the beginning, at which each cluster to have intra-class similarity. The algorithms begin with a best guess on the solution, and then refine the positions of cluster centres (i.e., TDA, NTDA) until reaching an optimum position. Clustering helps as a control tool (monitoring improvements in TDA's position controlling new condition-borne results) throughout the simulation cycles, and determines the new TDA groups (and its data) at each iteration cycle. With this process each of the succeeding iterations, that is a policy recommendation, produces a reduced TDA group with an improved outcome. Clustering plays a critical role as an objective function of the DIX methodology in finding the best solution through a systematic simulation evaluation, and reducing undesired results, just on the basis of monitoring the differences between NTDA and TDA's cluster centre values. This process is shown below:

$$
\begin{aligned}
\text { Min } C_{t}{ }^{\text {TDA }}-C_{t}{ }^{N T D A} & \rightarrow \text { stop process if } C_{t}{ }^{T D A}-C_{t}{ }^{N T D A}<0.05 \\
& \rightarrow \text { iteration should continue if } C_{t}{ }^{\text {TDA }}-C_{t}{ }^{N T D A}>0.05
\end{aligned}
$$

where $C$ is the overall cluster centre value (of all indicators, as in the output report of IBM-SPSS), with $t$ representing the $t^{\text {th }}$ time iteration, and superscript TDA showing the result of TDA groups, and NTDA of NTDA. Stability of the initial cluster centre results was not tested, to see whether clustering results would be different if they were to be changed, since the algorithm already seeks the best locations of the centres through the applied process. Each time clustering is executed as a result of simulated policy intervention different populations of TDA will form and impacted by the new situation's travel conditions. Consequently selecting new policies produces new P.data-to be used in the next simulation cycle.

\subsection{Policy simulation}

Policy simulations serve two purposes in the context of this study. The first purpose is to monitor the situation of the disadvantaged by the aid of the P.data evaluation, supported by the reclustering process that runs or stops the cycling process, and; see the costs and impacts of assumptive policy applications in the improvement of TDA's travels from the current situation. The second one is to maintain Pareto optimality, and that the proposed situation should not cause more congestion (considering only LOS) than the current situation. The assignment results are required for controlling the Pareto optimality condition on the network through the LOS indicator.

\subsection{Data requirement}

A new method of simulation is devised for the study as a result of the incompatibility issue of the existing method in the travel demand software-i.e., JICA-STRADA. In this new method the indicators (columns) and the trip impacts (rows) in the P.data matrix for each zone share the same preference rates in measuring both total improvements in TDA and total trip impacts as rates. A similar approach is used, by Lam and Xie (2002), in preference modelling of path choices of transit users for Singapore to determine transit paths if the conditions of transportation are to be improved using mixed stated and revealed P.data techniques. This exercise revealed that the single criterion of impedance is sufficient in choosing path or mode.

Impedance is not solely made up of time and cost. The novel idea of the study is based on the assumption that change in the travel situation of those TDA by each improvement caused by new policy scenarios dependently changes the satisfaction levels and preferences of this group. P.data provides the information, for some determined set of hypothetical conditions (which are identical with TDA indicators), on what the probability of change would be (trip rate doubles, costs reduce by half, or increase public modes or cycling). These probabilities are used later as the measure of impact for such policies. Disadvantage levels and probability shares, and thus their P.data, are expected to change each cycle, as depicted in Fig 2 . The preference probabilities are zone-aggregated for convenience. Once collected precisely, P.data guides simulations assuming that respondent preferences and reactions will remain constant over time.

It is essential that the stated preferences show the degree of probability that the chosen policy is most likely to be successful as far as the surveyed people's responses are reliable. By answering 'yes' as one option among the others (see Appendix 1 Part F), respondent readily assumes their disadvantage related to the condition that will be significantly reduced or removed once a solution is provided. At the same time, the improvements are most likely to cause impacts on the system such as increased trip rate, which will affect the next iteration. Not all people in the zone select to that particular option, some will prefer other impact options, and thus, accepting the option will be a gauge for TDA improvement. The degree of reducing disadvantages will vary across the indicators. Finally, for the combined index value, all obtained values from each indicator are summed up. 




Fig. 2. Calculation procedure of disadvantage improvement rates.

All participant responses are aggregated in the form of P.data matrices for each zone, columns showing index items (if-condition) of disadvantages and rows showing the possible trip impacts against the 'if conditions. 'Yes' responses of those who already satisfy the condition are eliminated-e.g., a person who already travels by bike answering 'yes' for the question of 'Do you prefer your travel mode to be walking or cycling?' is conflicting, thus their evaluation is removed. The zone-aggregated values from respondents in a zone are referred as 'zonal preference' or 'impact', and calculated as follows:

$I_{i}^{d}=\sum_{p} y_{p}$

for $\forall i \in Z$ for $y=1$, if $y=$ 'yes' selection exists for TDA, where $I$ represents zonal impact value, $i$ the counter of zone (Z), $d$ the counter of TDA person in zone, and $p$ the number of persons surveyed.

P.data matrix evaluation requires a set of rules for efficient goaloriented impact evaluation. One such adopted rule is satisfying optimum impact between indicators and trip impacts regarding to higher total impacts (above a defined value, or based on defined number of highest column and row sums) ever observed. Accordingly, the impact evaluation is based on two constraints: Indicators, and trip impacts. The total sum (i.e., improvement) should not exceed $100 \%$ impact in a run, as for Pareto optimality is concerned-or improvement rates should be introduced incrementally. For realistic probabilities, the final improvement rate

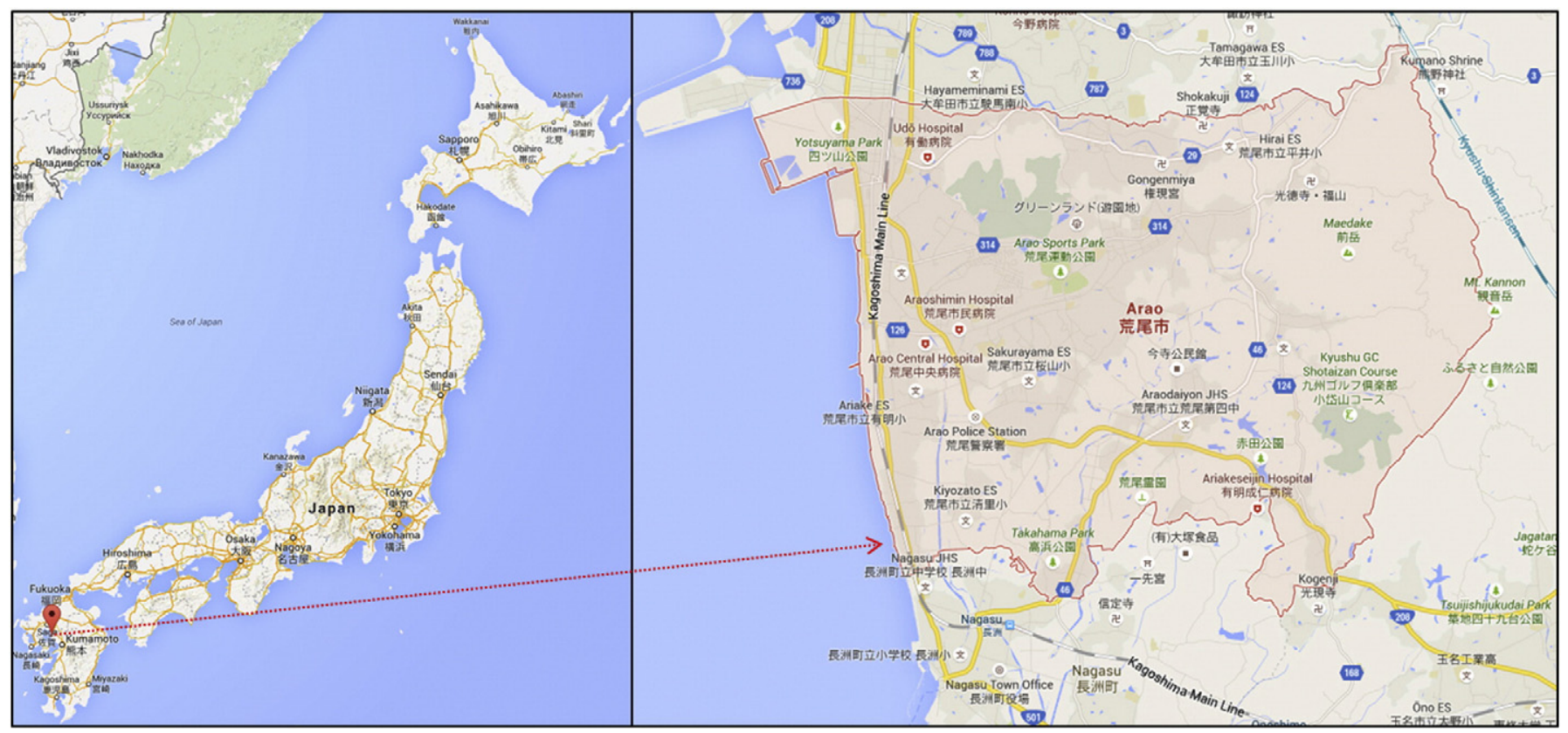

Fig. 3. Location of Arao. 


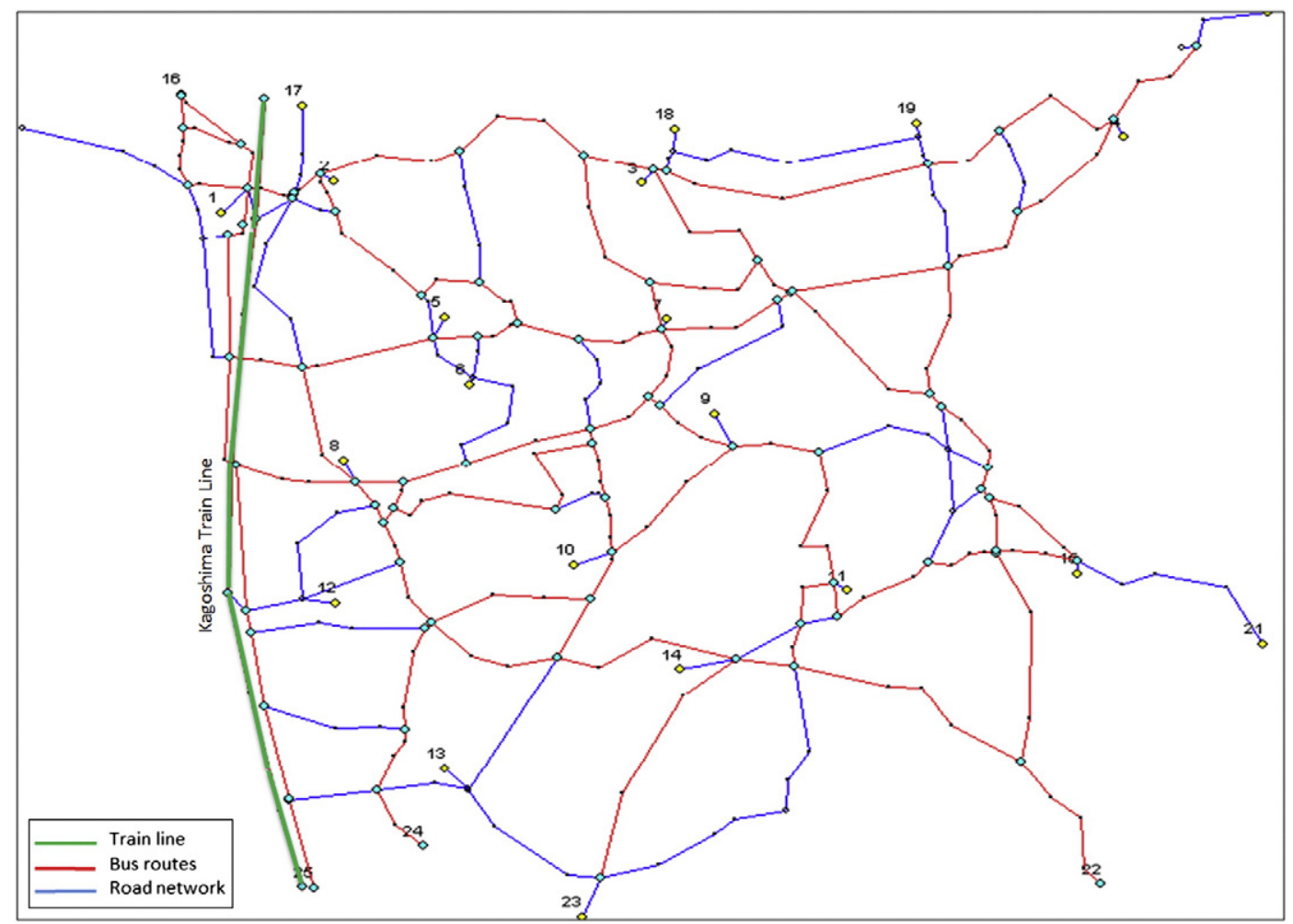

Fig. 4. Road network and public transport routes in Arao.

determined is multiplied by the cell's base occurrence probability-since there are five if-condition (composite) indicators and five impact reactions, which makes 25 possibilities of different impacts (i.e., $1 / 25$ number of cells in the matrix: 0.04 ).

\section{Pilot application of the approach}

\subsection{Study area}

The test bed town-Arao, a former mining town highly regarded as an important contributor to Japan's modernisation, and in decline since the closure of the coal mines in the late 90s-is chosen for its higher rate of elderly, disabled, and potentially TDA population, dispersed settlement structure, and heavily car-based transportation system that may cause barrier effect to TDA. The town is established on a land of about 5700 ha and has a population of 56,822 (in 2012) with 24,255 households and the density of about 9.97 persons/ha. The Ishaya Bay houses Arao in the northwest part of the Kumamoto Prefecture about $35 \mathrm{~km}$ from the city of Kumamoto (Fig. 3). Arao has a scattered settlement character, denser in two central areas, namely Midorigaoka and Yotsuyama. Average household size is 2.34. The elderly population ratio (above 65 years old) is $36.4 \%$-well above the national average of $31.3 \%$. Unemployment rate $(9.1 \%$ of the working age population) is quite high compared to other parts of Japan. Arao is currently served with 29 public transport routes one being intercity train line and the rest bus network, where five of them are intercity routes (Fig. 4).

\subsection{Data collection and analysis}

A household travel survey is conducted to obtain necessary data to test run the indexing approach in Arao between April and May 2012. In total 1069 households are invited to take part in the household travel survey that contains 56 questions (see Appendix 1). The selection of the households is done based on the stratified random sampling method-considering the age, gender and income levels of the districts of Arao. The self-administered surveys are conducted through postal mail, and executed for each member of the household. The survey data are parted into two groups as general household-level data for household specific information and personal data for individual specific information. Among those invited 663 responded to the survey (62\% response rate), where 627 of valid responses are processed, which equates to 1342 individuals with $2.4 \%$ sampling rate, making an average of 89.5 observations per zone-total of 15 zones (Table 2 ). Through this exercise, travel characteristics of participants-trip details for the week prior to the survey-are captured along with their preferences for TDA

Table 2

Household survey summary.

\begin{tabular}{llcclc}
\hline $\begin{array}{l}\text { Zone } \\
\text { number }\end{array}$ & Zone name & Population & $\begin{array}{l}\text { Response } \\
\text { rate }\end{array}$ & $\begin{array}{l}\text { Sample } \\
\text { ratio }\end{array}$ & $\begin{array}{l}\text { Disable population } \\
\text { \& rate }\end{array}$ \\
\hline 1 & Yotsuyama & 5577 & 98 & 0.018 & $18(\% 18)$ \\
2 & Manda & 4948 & 86 & 0.017 & $12(\% 14)$ \\
3 & Ide & 5184 & 172 & 0.033 & $31(\% 18)$ \\
4 & Hirayama & 2357 & 60 & 0.025 & $6(\% 10)$ \\
5 & Kunai & 2,930 & 123 & 0.042 & $21(\% 17)$ \\
6 & Arao Centre & 7217 & 101 & 0.014 & $9(\% 9)$ \\
7 & Midorigaoka & 896 & 65 & 0.072 & $6(\% 9)$ \\
8 & Masunaga & 5407 & 103 & 0.019 & $17(\% 16)$ \\
9 & Kawanobori & 4846 & 69 & 0.014 & $16(\% 23)$ \\
10 & Sakurayama & 3032 & 46 & 0.015 & $8(\% 17)$ \\
11 & Hatimandai & 3084 & 45 & 0.015 & $10(\% 22)$ \\
12 & Ariake & 3399 & 116 & 0.034 & $22(\% 19)$ \\
13 & Kiyosato & 2965 & 82 & 0.028 & $4(\% 5)$ \\
14 & Hatiman-Yahata & 3538 & 142 & 0.040 & $15(\% 11)$ \\
15 & Fumoto & 1525 & 33 & 0.022 & $5(\% 15)$ \\
Total & & 56,905 & 89.4 & 0.024 & $200(\% 15)$ \\
\hline
\end{tabular}


Table 3

Travel characteristics of Arao.

\begin{tabular}{|c|c|c|c|c|c|}
\hline Trip rate by purpose & Trip rate by mode & Modal share & Average trip length and cost & Number of transit lines & Traffic problems \\
\hline Work: 0.67 & Walk \& cycle: 0.25 & Walk \& cycle: $13 \%$ & Work: $12.1 \mathrm{~km} / 282 ¥$ & 23 inner and & Peak hour congestion in \\
\hline All other: 0.73 & Private: 1.61 & Private: $81 \%$ & All other: $10.5 \mathrm{~km} / 217 ¥$ & 6 external & central locations \\
\hline Return: 0.69 & Public: 0.13 & Public: $7 \%$ & Return: $11 \mathrm{~km} / 276 ¥$ & & \\
\hline Total: 2.13 & & & & & \\
\hline
\end{tabular}

indexing. Of the sampled population, overall household size is 2.7, average age is 50.5 , gender distribution is $51 \%$ female and $49 \%$ male, car ownership per household is 1.85 (self-owned automobile and/or company car), bicycle and/or motorcycle ownership is 1.51 , and annual average household income per capita is JPY 3,215,236 (about USD 27,000). Major trip purposes used in this study are 'work' (composed of commuting and business trips), 'all other' (all social, recreational, and health related trips), and 'return' trips (all home returning trips). The OD data of all trips and mode combinations are formed. Major modes used are 'private' (private car, ride given, motorbike trips), 'public' (bus, train), and 'walk \& cycle' trips (Table 3).

DIX values are obtained to measure disadvantage levels in terms of five pre-defined composite indicators, and are used as zone aggregations (mean averages). After calculating DIX values for each composite indicator, they are ready for the cluster analysis for determining TDA. The initial cluster centre results, based on five composite indicators and different trip purposes are presented in Table 4. For work trips, there are 699 persons assigned to the TDA category out of 1341 (52\% of all population), while the figure for all other trips is 633 persons (47\%). Return trips are omitted from analysis due to inconsistency in the results-i.e., 'TravQual' indicator not providing reliable findings for TDA in return trips. According to the cluster centre results TDA is not disadvantaged in terms of 'TrSysQual' indicator for all trip purposes. Thus, in the P.data evaluation and related simulation stage, this indicator is discarded. Based on these findings it is possible to say about half of the Arao people are TDA (see Fig. 5).

\subsection{Traffic assignment}

This study only concerns of the traffic assignment stage of the classical four-step modelling since the impacts of current traffic are investigated. Taking only the last stage of modelling is meaningful because of the sufficiency of this stage in terms of operable parameters is used in simulations free from the other modelling stages. The transit assignment is also required for interaction between model's inputs and outputs. The necessary data for the current traffic assignments includes mode and purpose matrices of both TDA and NTDA populations, and their impedance matrices (min. route distance impedance), which adds up to 15 OD matrices in total, each calculated in JICA-STRADA. Separate cost data are used for private and public mode choice models. The focus trip purposes are 'work' (commuting and business) and 'all other' (social, health and recreational) trips; and 'return' trips are not subject to the modelling for TDA for some complications, but for total trip balances, their traffic loads and impacts are calculated in the assignments stage.

In JICA-STRADA software, TDA and NTDA segregations are treated for all trip purposes. However, they merge and share the same impedances (TCI) bound to the same mode. TCI impedances, thus, are treated separately for TDA and NTDA. Finally, all purposes are merged, excluding the 'walk \& cycle' trips, and combined two modes (private and public) are introduced into the software's assignments module. For the traffic assignment stage, the ArcGIS network files of links, nodes, and their related data are entered through the Network and Transit Line editor modules.

\subsection{Simulation package}

The research utilised JICA-STRADA for traffic assignments and simulations to see the impacts of improvements made to TDA. The software was developed by the Japanese International Cooperation Agency (JICA) for major transportation projects with application areas of environmental impact, travel demand, and cost-benefit analyses (Vergel and Tiglao, 2005).JICA-STRADA has 17 modules for various aspects of travel demand analyses. In this research, trip OD matrices, impedances, and network attributes datasets are used. As of the simulation evaluator tools, the following display results are utilised: traffic volumes, LOS, speed, modal shares, and comparison of two assignments.

\section{Study findings}

\subsection{Index results}

Using the previously described method, normalised DIX values are obtained for disadvantage control for $(t)$ iteration. The base-case TDA and NTDA population DIX values for each zone by trip purpose ('work', 'all other') are provided in Table 5. Findings indicate that the disadvantaged discrepancy is rather strongly observed at 'work' trips, instead of 'all other' trips, which means that those trips pose more challenge in easing disadvantages. If the DIX values of even those of NTDA show improvement, as an outcome of the simulation procedure, the threshold/benchmark scores should be increased inevitably.

\subsection{Impact of data on the results}

The base P.data values (improvement rates) were obtained from composite indicators and trip impacts for both 'work' and 'all other' trips for each zone. Trip impacts are the basic travel demand impacts on the existing traffic and network, causing alterations in policy magnitudes (ratio increases) of concerned indicators. Consequently, policy analysts can observe positive or negative effects to the current system (LOS and impedance) to which improvement considered for TDA by effective policy measures.

P.data values are gathered as the sum of 'yes' responses only from TDA persons. Since it is a ratio value, it can comfortably be integrated

Table 4

Cluster centre results.

\begin{tabular}{|c|c|c|c|c|c|c|}
\hline & \multicolumn{2}{|c|}{$\begin{array}{l}\text { Cluster centre } \\
\text { value for 'work' }\end{array}$} & \multicolumn{2}{|c|}{$\begin{array}{l}\text { Cluster centre } \\
\text { value for 'all other' }\end{array}$} & \multicolumn{2}{|c|}{$\begin{array}{l}\text { Cluster centre } \\
\text { value for 'return' }\end{array}$} \\
\hline & TDA & NTDA & TDA & NTDA & $1^{*}$ & $2^{*}$ \\
\hline Access & .47 & .86 & .48 & .70 & .61 & .87 \\
\hline LandEnv & .43 & .74 & .44 & .60 & .55 & .76 \\
\hline PhysBarr & .57 & .85 & .60 & .95 & .34 & .80 \\
\hline TravQual & .84 & .90 & .86 & .91 & .85 & .82 \\
\hline TrSysQual & .83 & .62 & .88 & .66 & .86 & .59 \\
\hline Overall & .60 & .81 & .62 & .84 & .64 & .77 \\
\hline
\end{tabular}

* The cluster could not be classified as TDA or NTDA. 


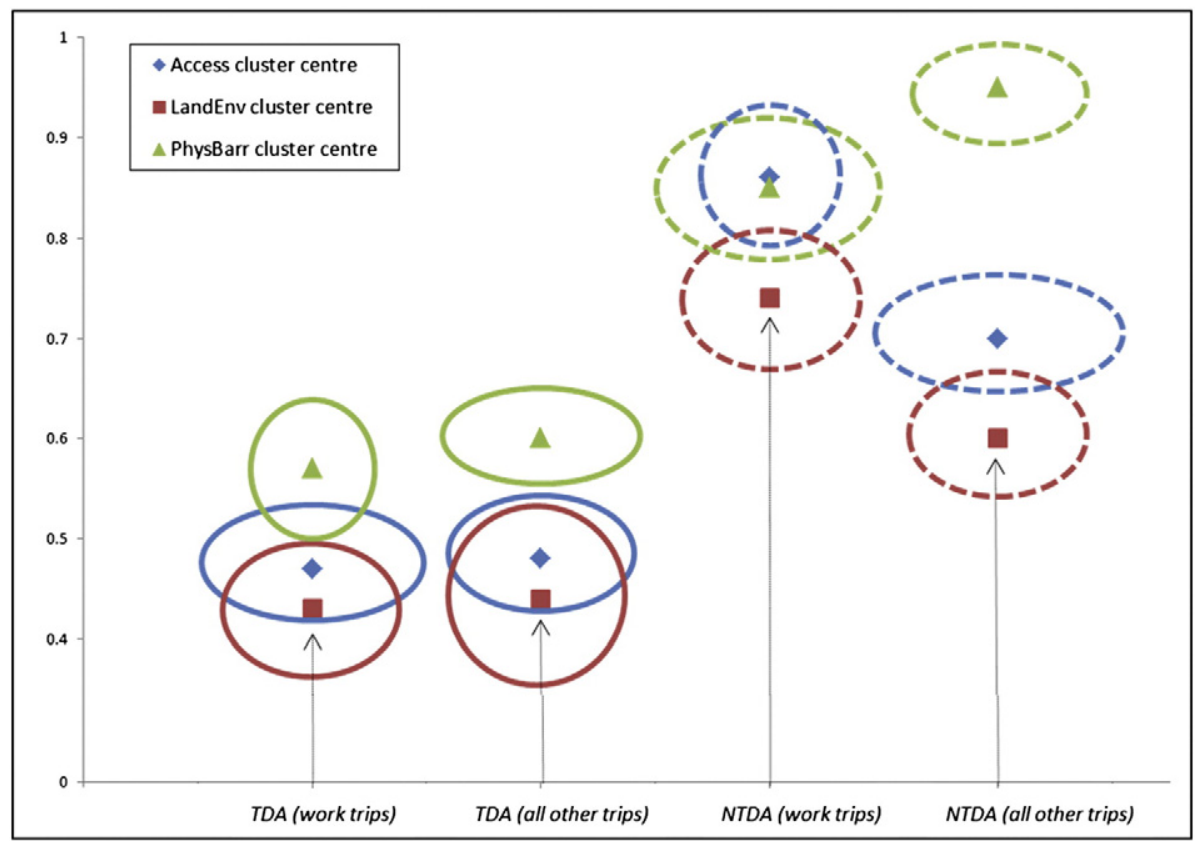

Fig. 5. Simplified cluster scatter plot.

into TDA improvement measurements, which are also ratio values. Thus, a gauge is obtained to observe likelihood of policy impacts when the policy is supposed to be in effect. Having obtained P.data from the observed TDA, significance of preferences is evaluated in three steps:

(i) Reliability weights of impacts: Weights of impacts are found by multiplying the sample size and P.data values by the impacts. Only the values above a certain threshold value $(0.2$, equal weighing) are assumed to be a reliable cumulative response.

(ii) P.data ratio values and choosing the most significant: The rate for each indicator-impact pair is found by dividing the individual (cell) P.data value to those impact sums, where the sum must add up to 1 . Across these P.data ratios, the maximum values are marked as the significant for each indicator (i.e., if-condition). These are the maximum ratio values for the obtained indicators.

(iii) Nominating appropriate policy indicators by zone: To find the most appropriate policy approaches, starting from the applicable (as some indicators or impact areas may not be practical to treat) maximum value, high ratios are chosen for each indicator until the sum of all chosen values increase to 1. Finally, for the chosen significant ratios, all impact rates are summed, each multiplied by the cell's natural occurrence probability among others, which is 0.04 ( 0.2 for 5 indicators and 0.2 for 5 trip impacts; $0.2 \times 0.2=0.04$ ) and added to the DIX value of TDA in order to see whether it gets close to the NTDA DIX value.

$P_{v t}^{i}=\sum_{m=1}^{n} f_{v}^{i}$

for $\mathrm{m}=1,2, . . \mathrm{n}$ and for $i \in Z$

where, $P$ is the probability of the concerned $v t$ pair preference value for the $i^{\text {th }}$ zone among all (Z), $v$ is indicator vector, and $t$ is the trip impact vector, $f$ is the existence of impact for the indicator (if-condition), and $n$ is the total number of TDA observations $(m)$ in the concerned zone $Z$.

Table 5

Improved index values.

\begin{tabular}{|c|c|c|c|c|c|c|}
\hline \multirow[t]{2}{*}{ Zones } & \multirow[t]{2}{*}{ NTDA (work) } & \multirow[t]{2}{*}{ TDA (work) } & \multirow[t]{2}{*}{ NTDA (all other) } & \multirow[t]{2}{*}{ TDA (all other) } & \multicolumn{2}{|c|}{ Policy indicators that work best for improvement } \\
\hline & & & & & For work trips & For all other trips \\
\hline 1 & $0.72-\mathbf{0 . 7 5}$ & $0.67-0.72$ & $0.72-0.75$ & $0.66-\mathbf{0 . 7 1}$ & Access, TravQual & Access, TravQual \\
\hline 2 & $0.69-\mathbf{0 . 7 3}$ & $0.61-\overline{\mathbf{0 . 6 8}}^{*}$ & $0.70-0.71$ & $0.69-\overline{\mathbf{0 . 7 1}}$ & Access, TravQual & TravQual \\
\hline 3 & 0.79 & $0.63-\mathbf{0 . 7 4}$ & $0.71-0.73$ & $0.69-\overline{\mathbf{0 . 7 2}}$ & Access, LandEnv, TravQual & Access, TravQual \\
\hline 4 & 0.79 & $0.61-\overline{\mathbf{0 . 7 1}}^{*}$ & $0.74-0.76$ & $0.74-\overline{\mathbf{0 . 7 9}}^{\mathrm{a}}$ & Access, LandEnv & Access, TravQual \\
\hline 5 & 0.73 & $0.63-\underline{\mathbf{0 . 7 0}}$ & $0.68-0.71$ & $0.63-\mathbf{0 . 6 8}$ & Access, TravQual & Access, TravQual \\
\hline 6 & 0.79 & $0.65-\overline{\mathbf{0 . 7 0}}$ & $0.69-\mathbf{0 . 7 2}$ & $0.65-\overline{\mathbf{0 . 7 0}}$ & TravQual & TravQual \\
\hline 7 & 0.78 & $0.69-\mathbf{0 . 7 5}$ & $0.76-\mathbf{0 . 7 8}$ & $0.67-\mathbf{0 . 7 2}$ & Access, TravQual & Access, TravQual \\
\hline 8 & 0.73 & $0.63-\overline{\mathbf{0 . 6 6}}$ & $0.71-0.72$ & $0.69-\mathbf{0 . 7 0}$ & TravQual & TravQual \\
\hline 9 & 0.75 & $0.60-\mathbf{0 . 6 4}$ & $0.74-0.76$ & $0.67-\overline{\mathbf{0 . 7 3}}$ & LandEnv & PhysBarr \\
\hline 10 & 0.75 & $0.66-\mathbf{0 . 7 1}$ & $0.71-0.75$ & $0.66-\overline{\mathbf{0 . 7 3}}$ & Access & Access, TravQual \\
\hline 11 & 0.76 & $0.65-\overline{\mathbf{0 . 7 2}}$ & $0.71-0.74$ & $0.65-\overline{\mathbf{0 . 7 2}}$ & PhysBarr, TravQual & Access \\
\hline 12 & 0.74 & $0.62-\overline{\mathbf{0 . 7 2}}$ & 0.71 & $0.63-\overline{\mathbf{0 . 6 8}}$ & Access, landenv, TravQual & Access, TravQual \\
\hline 13 & $0.69-\mathbf{0 . 7 0}$ & $0.56-\overline{\mathbf{0 . 6 6}}$ & $0.64-0.68$ & $0.58-\overline{\mathbf{0 . 6 5}}$ & Access, TravQual & Access \\
\hline 14 & 0.73 & $0.63-\overline{\mathbf{0 . 6 9}}^{*}$ & 0.72 & $0.62-\overline{\mathbf{0 . 6 8}}^{*}$ & Access, TravQual & Access, TravQual \\
\hline 15 & $0.68-\mathbf{0 . 6 9}$ & $0.62-\mathbf{0 . 6 8}$ & 0.64 & $0.53-\mathbf{0 . 5 8}$ & Access, TravQual & Access \\
\hline Average & 0.74 & $0.63-\overline{0.70}$ & 0.71 & $0.65-0.70$ & Usually Access, TravQual & Usually Access, TravQual \\
\hline
\end{tabular}

* Indicates a good improvement, but not efficient to satisfy 0.05 convergence due to the difference between TDA and NTDA.

a Shows an over-improvement on results even beyond the new recorded NTDA value, thus, considered as inappropriate. 


\subsection{Origin-destination matrix results}

In total 15 OD matrices by mode (private, public, walk \& cycle), purpose (work, all other, return), and person type (TDA and NTDA) are constructed (Table 6). These matrices are introduced to the assignment module of the software as merged private and public trips ('walk \& cycle' trips are not taken since no impedance evaluation is possible). The following are the specifications of basic link attributes: QV type link cost function is utilised (i.e., BPR cost function); time value for the private mode is taken as $0.0159 \mathrm{JP} ¥ / \mathrm{sec}$ (standard for Japan) and average passenger occupancy rate is assumed 1.2 per car; time value of transit general for Japan, 0.0019 is used; Average occupancy is 15 passengers; There are 28 transit (bus) lines serving the area, of which five outstretch the boundaries of Arao, and general bus frequency is taken as a range between 1 and 15 per hour; The passenger capacity is 80 pass/veh, and; the speeds are $30 \mathrm{~km} / \mathrm{h}$ for private car, $40 \mathrm{~km} / \mathrm{h}$ for transit bus (min: 5 , max: 60 ), $60 \mathrm{~km} / \mathrm{h}$ for train, and $5 \mathrm{~km} / \mathrm{h}$ for walking.

Modal shift directions from 'private' to 'other' modes are determined according to the distance criterion of the travels made; closer trips may shift to 'walk \& cycle' trips, and the farther trips to the 'public', if any improvement occurs. The first 'trip impact' is the general trip rate increases (both 'work' and 'all other' simultaneously), then the trip cost decreases, and the modal shifts occur between three modes. In the case of TDA conditions being improved through policy measures, only the shifts from 'private' to 'public' and to 'walk \& cycle' modes are expected. 'Public' mode only shifts to 'walk \& cycle' mode. No mode shifts to 'private', since more use of private car is not seen as an improvement due to being a non-idealistic (unsustainable) solution. Similarly, 'walk \& cycle' can shift only to 'public' mode. Finally, as the third shift type, shifts can occur from 'work' purpose to 'all other', due to the latter representing leisure trips that TDA would choose, in case of improvement. In a simulation, the trip impacts such as trip increase, modal shift, purpose shift and impedance effects are subject to change, thus only the compilation of the related OD matrices for TDA are required, because with the Pareto optimality rule adopted, the policy analyst is only allowed to make changes on the trips or impedances of TDA, and not NTDA.

\subsection{Simulation results}

A single simulation trial was sufficient to improve most of the zones' disadvantage levels within the 0.05 convergence level. Further simulation trials would have been required and thus more iterations, if this convergence value was lower. Since the overall tzDIX difference between TDA and NTDA is less than 0.05 for all zones, the process was stopped and best working strategies were nominated accordingly. In Table 5, bolded figures show the improved DIX values in composite indicators for the concern zones by the simulation policy measures. In the same table successful (within the convergence value) improvements are underlined, and policy indicators that are best for improvement are shown. Simulation findings suggest that 'Access' and 'TravQual' are the indicators to focus on. Results of the zones satisfy the convergence criterion, thus, the best working policies for Arao can be announced without running another simulation and re-clustering processes.
When trip impacts are analysed, hypothetical application of policies favouring TDA induced more trips from TDA (trip rate increase), which is likely to happen when the conditions are improved (see Cervero, 2003; Duvarci and Mizokami, 2007). According to simulation results, affected from the respected amount of change in policies, Table 7 explicates the total trip changes for only TDA showing serious trip shifts at modes and purposes. The most impact is seen in 'walk \& cycle' trips of 'all other' with an $85 \%$ increase. All these changes have some consequences on the current impedances and LOS, and the employed software can calculate these costs. The only way to integrate the impedance impact is the subtraction (if increased impedance) or addition (if reduced impedance) to the latest zonal disadvantage (zDIX) impedances. Since the impedance changes are trivial, they do not impose serious impact on the system.

When the impacts of simulations are analysed, an interesting result became noteworthy; improvements made for TDA actually relieved the traffic load (see Duvarci and Mizokami, 2009) on the links to the trivial extent, most probably due to the modal shifts to the public mode from private due to the increased quality and attractiveness of public transport as a result of policy measures. Still, the most crucial finding remains to be that there are not great differences between the base and simulation assignments. As of the changes in TCI impedance, in general reductions in the impedances out of the simulation were observed. Simply these impedance reduction rates were added to the ratio values of DIX values, but, since the reductions are trivial, they do not make any difference in the DIX values. As the DIX values are origin-based, average value per origin zone are used as shown in Appendix 2. The impacts of the simulation results on the traffic loads were observed to be trivial-only on several links traffic loads are increased but all being under the service capacity limits of these links (see Fig.6, where increased traffic volumes are shown with thicker links).

After selecting the most viable policy, their relative importance is measured by the ratio totals. In Appendix 3, the respective policy indicator ratio totals, i.e., weights, are determined for each zone, and listed by trip purpose for comparison. Another outcome of the simulation stage is that policymakers to focus on underlining the importance of accessibility provision. In Arao, 'LandEnv' and 'PhysBarr' related indicators are captured as problematic issues in Zones 3, 4. 9, 11, and 12. These zones are relatively fringe places that indicate some infrastructure complications. The improvement in 'PhysBarr' would most probably benefit the elderly, the disabled and children. Fig.7 highlights the location of zones with most significant TDA populations when work and all other trips are concerned-size of the circles represents relative magnitude of the disadvantage issue.

\section{Conclusions}

The literature highlights social impacts, distributional effects and consequences of transport decision-making on TDA populations (Jones and Lucas, 2012). The research reported in this paper introduces a disadvantage-impedance indexing approach that aims to reduce the disadvantage levels of TDA populations through policies tested in a simulation environment. This approach is put under the microscope in the test bed of Japanese town of Arao (a super-aged community) for

Table 6

Trip impacts.

\begin{tabular}{|c|c|c|c|c|c|c|c|c|c|c|}
\hline & \multicolumn{5}{|c|}{ Work trips } & \multicolumn{5}{|c|}{ All other trips } \\
\hline & Base & Trip increase* & Mode shift ${ }^{*}$ & Purpose shift ${ }^{*}$ & $\%$ change & Base & Trip increase* & Mode shift ${ }^{*}$ & Purpose shift* & $\%$ change \\
\hline Private & 18,555 & 19,017 & 18,825 & 18,591 & +0.20 & 28,016 & 31,082 & 27,876 & 28,623 & +2.20 \\
\hline Public & 2695 & 2939 & 3096 & 3053 & +13.30 & 971 & 1059 & 1240 & 1283 & +32.10 \\
\hline Walk \& cycle & 3950 & 3605 & 4186 & 4135 & +4.70 & 2137 & 3915 & 3903 & 3954 & +85.00 \\
\hline
\end{tabular}

* Total trips change after the trip rate increases, and modal shift and trip purpose also shift respectively. 
Table 7

Trip impact increase rates.

\begin{tabular}{llllll}
\hline Zones & $\begin{array}{l}\text { Work trip } \\
\text { rate }\end{array}$ & $\begin{array}{l}\text { Work } \\
\text { mode }\end{array}$ & Purpose-common & $\begin{array}{l}\text { All other } \\
\text { trip rate }\end{array}$ & $\begin{array}{l}\text { All other } \\
\text { mode }\end{array}$ \\
\hline 1 & 0.018 & 0.007 & 0.015 & 0.013 & 0.008 \\
2 & 0.020 & 0.015 & 0.013 & 0.015 & 0.010 \\
3 & 0.024 & 0.021 & 0.023 & 0.017 & 0.010 \\
4 & 0.015 & 0.020 & 0.018 & 0.017 & 0.018 \\
5 & 0.021 & 0.012 & 0.015 & 0.009 & 0.012 \\
6 & 0.030 & 0.012 & 0.011 & 0.009 & 0.010 \\
7 & 0.015 & 0.009 & 0.015 & 0.011 & 0.010 \\
8 & 0.011 & 0.010 & 0.010 & 0.011 & 0.010 \\
9 & 0.007 & 0.010 & 0.025 & 0.008 & 0.009 \\
10 & 0.007 & 0.005 & 0.010 & 0.024 & 0.004 \\
11 & 0.015 & 0.010 & 0.010 & 0.007 & 0.040 \\
12 & 0.024 & 0.023 & 0.020 & 0.018 & 0.012 \\
13 & 0.029 & 0.016 & 0.015 & 0.018 & 0.014 \\
14 & 0.013 & 0.011 & 0.014 & 0.014 & 0.010 \\
15 & 0.010 & 0.012 & 0.016 & 0.000 & 0.013 \\
\hline
\end{tabular}

assessing its capabilities in reducing transportation policy shortcomings by selecting effective policies, and evaluating its operational integrity to mainstream four-step travel demand modelling with JICA-STRADA software.

The pilot study investigation demonstrates the appropriateness of the approach. The findings show that the base index values do not present large differences between the TDA and NTDA groups in Arao. This can be explained by more than one-third of the population being elderly in Arao, and the high quality of Japanese public transport systems limiting TDA in the community. Thus, only through single simulation round all zones are succeeded to the acceptable convergence criterion of 0.05 . The investigation generates the following insights from the pilot investigation:

(i) Overall improvement levels are moved up from 0.63 to 0.7 (\%11), and from 0.65 to 0.7 (\%7.7) for 'work' and 'all other' trips respectively-meaning the approach made a positive impact;

(ii) Work trips almost satisfy the convergence criterion (5.4\% difference between NTDA and TDA groups), while 'all other' trips almost fully ( $1.4 \%$ difference) satisfy the criterion at the end of a single simulation-meaning policy action needs to further focus on commuters' disadvantages;

(iii) Improvements especially in 'Access' and 'TravQual' composite indicator related issues are found to make a difference around $2-3 \%$ respectively from the current situation that can significantly contribute in easing disadvantages-meaning accessibility and travel quality are marked as the key policy areas;

(iv) For some fringe zones, 'PhysBarr' (around 0.05) and 'LandEnv' related (around 0.04) indicators underline significant issues-meaning physical barriers and land use and environmental conditions are also qualified policy target areas;

(v) As 'TrSysQual' composite indicator is already dropped from the simulation evaluation, since TDA values were already equal or better than NTDA for this policy indicator-meaning no policy action is needed in this area as transport system quality is above the world standard in Japan. Even they at the first glance this indicator seems to be problematic in the Japanese context, it is particularly meaningful in the context of developing countries where there is greater diversity of travel experiences and service quality are in many cases much lower, and;

(vi) The impacts of policy improvements to the current demands are evaluated by using impact ratios and the findings revealed an increase of trip rate by $20 \%$ and impedance by $5 \%$, and furthermore,

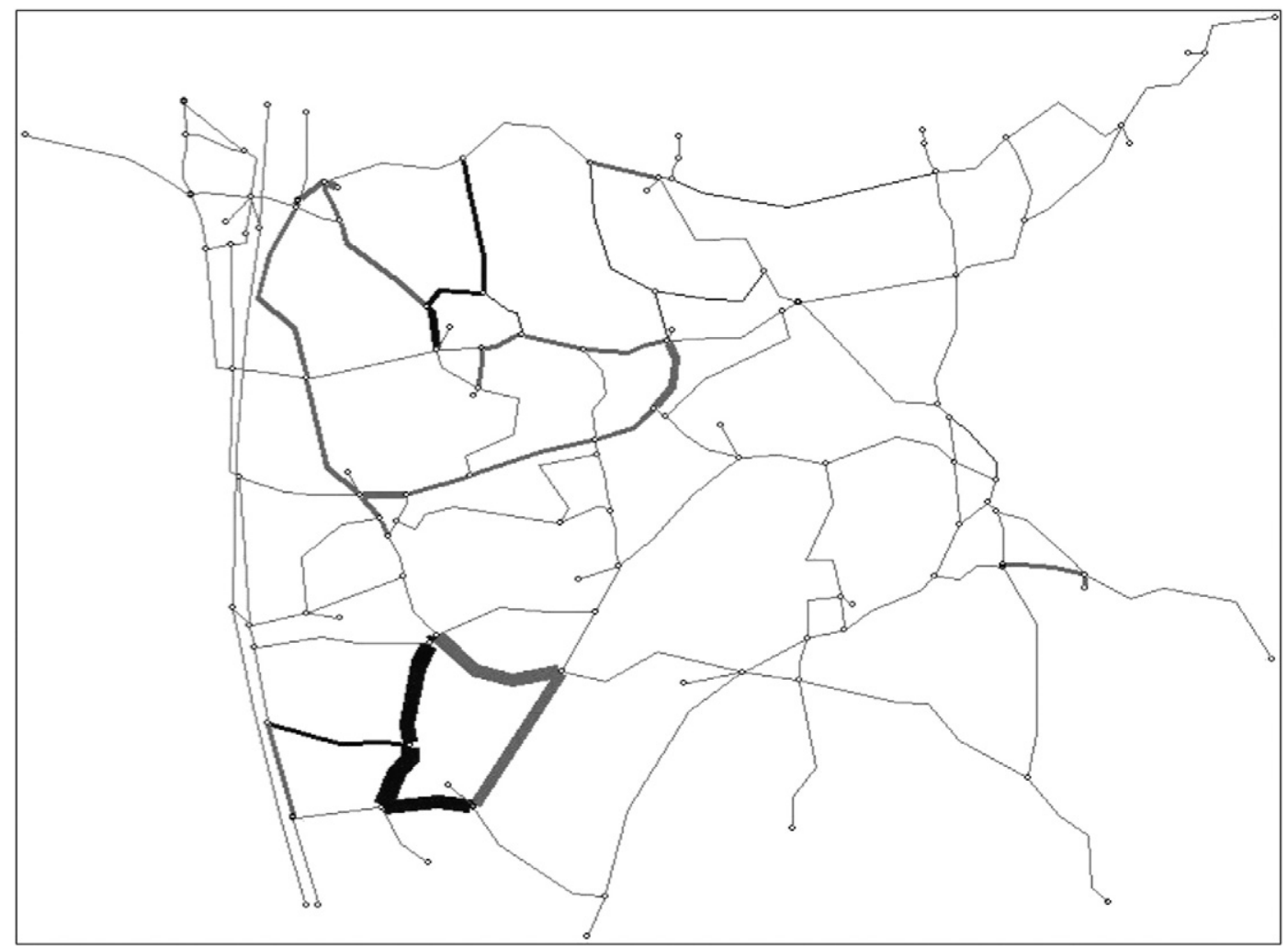

Fig. 6. Simulated traffic loads. 


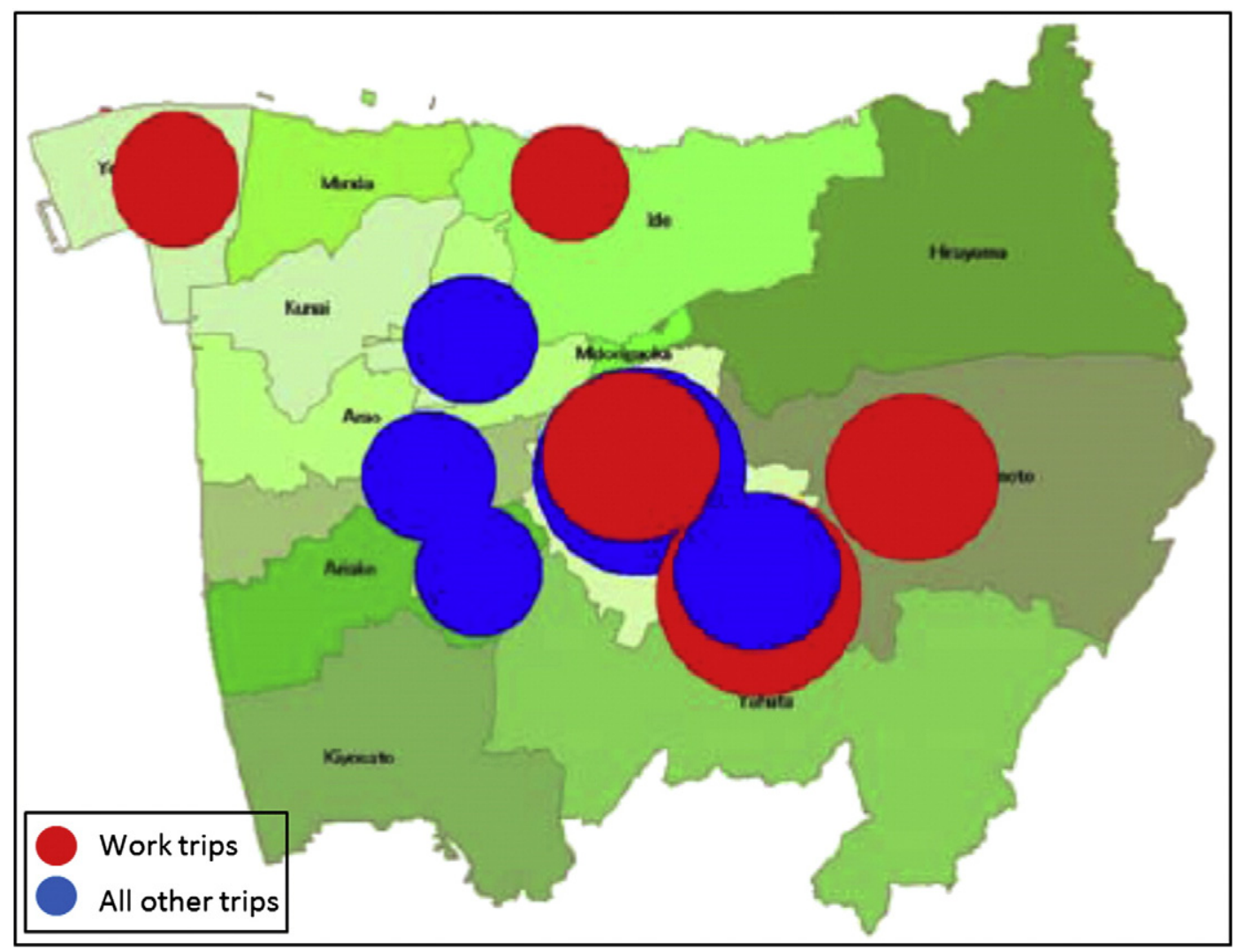

Fig. 7. Zones with significant TDA populations.

$30 \%$ of trips are shifted from 'public' to 'walk \& cycle' and 10\% from 'work' to 'all other' trips-meaning improving the conditions of TDA increases their trips, however, at the same time it relieves the traffic amount by shifting them to sustainable transport modes.

These insights indicate that the criteria considered for the proposed indexing approach is efficient in capturing potentially effective policy directions to combat TDA problem. Thus, the research reveals the potential of the approach for implementation in other case studies and elsewhere than Japan, where depending on the local context the approach might need to be run several cycles until satisfactory results are produced in simulations to bring TDA population up/close to the level of NTDA. The approach presented in this paper provides a costeffective way in producing sound policies-with reduced time for running simulation trials; and integration of this approach, and inclusion of social issues, as equity, into four-step sequential models is advocated, which helps automating TDA concerns directly into transportation modelling and planning. This way, policymakers and planners can benefit from the approach that offers a convenient method in reducing policy shortcomings particularly targeting transportation disadvantage issues.

Despite to the promising aspects of the proposed approach, it has some limitations. Firstly, the simulation method proposed in this paper is specifically designed for the TDA-based modelling particularly in the context of Japan, and may not always perfectly fit in other applications elsewhere without modifications to tailor it to the local context. Nonetheless, the study still revealed important insights on what might have happened to the TDA groups through this simulation approach. Secondly, the suitability of the proposed simulation approach is currently limited to the TDA modelling with JICA-STRADA. Presently, fitting the approach into other practical and operational systems or models might require further customisation. Thirdly, some software handling and/or compatibility limitations occurred while applying the simulation method, and the approach has limitations in verifying the simulation results with the real-life results. Last of all, consequences of the simulated improvements in mobility for the different groups of population are not provided as different TDA groups are not separately examined in the simulation analyses, such as elderly, young, disabled, and unemployed populations.

In consideration of these limitations, our future research direction will include developing a more devoted definition of zDIX and impedance values, investigating the impacts of simulated improvements on different TDA groups, and determining variable weightings for composite and individual indicators. Furthermore, testing the sensitivity and correlation of the selected indicators and their weighting assignments will be part of our future research plans. Finally, the prospects for the proposed approach to potentially become a commercial offthe-shelf TDA policy software package include the following impending improvements: Standardising and giving an automated structure to the approach; Routinizing the collection of data and data processing; Embedding the process into commercial software, and; Linking with GIS-based model applications for visualising demand and supply gaps for efficient provision of the services.

\section{Acknowledgements}

The authors wish to acknowledge the financial and/or in-kind support received from their institutions to undertake research reported in this paper. The authors are also grateful to the editor and anonymous reviewers who provided constructive comments on an earlier version of the paper. 


\section{Appendix 1. Household travel survey questionnaire}

Part A: Household profile and travel characteristic evaluation

1) What is your home address?

2) What is your household size?

3) What are the ages of your household members?

4) What are the genders of your household members?

5 ) Is there anyone with disability in your household?

6) What are the occupations of your household members?

7) What is the total income of your household?

8) How many motor vehicles are owned in your household?

9) How many people hold car licence in your household?

10) What are the education levels of your household members?

11) What is your daily trip frequency?

12) What are your daily travel destinations?

13) What are your daily trip modes?

14) What are your travel departure times?

15) What is your daily travel length?

16) What are your daily travel durations?

17) What are your trip fares and total daily travel cost?

18) How many transfers do you make in your daily travels?

Part B: Accessibility evaluation

19) What is your estimated accessibility level to job or school?

20) What is your estimated accessibility level to hospital or medical centre?

21) What is your estimated accessibility level to shopping centre?

22) What is your estimated accessibility level to park and recreational activities?

23) What is your estimated accessibility level to social, cultural or religious activities?

24) What is your estimated accessibility level to transport facilities from home?

25) What is your estimated accessibility level to transport facilities from work or school?

Part C: Land use and environmental condition evaluation

26) How do you view your residential neighbourhood in an appropriate place in terms of connectivity, transport facilities and travel cost and easiness to other parts of the town and major activities?

27) How do you view your work/school environment as an appropriate work/study place in terms of connectivity, transport facilities and travel cost and easiness to other the town and major activities?

28) How comfortable are you when walking, and find walking enjoyable because of the surrounding attractions?

29) How frequent do you use walkways or bikeways?

30) What is the level of lighting on the streets and do you feel safe at nights while walking?

31) How dense the built form and traffic levels in your neighbourhood?

Part E: Physical barrier evaluation

32) What is the level of steep slopes in your neighbourhood?

33) What is the level of narrow roads in your neighbourhood?

34) What are the conditions of sidewalks in your neighbourhood making walking unpleasant?

35) What are the road conditions in your neighbourhood making driving not easy?

36) What are the other barriers in your neighbourhood such as nondropped curbs at sidewalks, no trees, shade or shelter to protect from weather conditions?
37) What are the level of traffic interruptions and traffic lights in your neighbourhood?

38) What are the information and guiding signals availability in your neighbourhood?

Part D: Travel quality evaluation

39) How do you evaluate the walking distance to the nearest public transport stop?

40) How do you evaluate your estimated daily travel length, travel durations, trip fares and total cost?

41) How do you evaluate the number of daily transfers you make?

42) How do you evaluate the distances to your destination from the car park or public transport stop?

43) How do you evaluate your daily transport conditions, such as travel quality and satisfaction level?

Part E: Transport system quality evaluation

44) How do you evaluate the walking distances to available public transport modes?

45) How do you evaluate the availability of public transport modes and options for your trips?

46) How do you evaluate the physical conditions of public transport stops based on your daily experience?

47) How do you evaluate the reliability and frequency of the public transport system based on your daily experience?

48) How do you evaluate the seat availability and comfort in the public transport system based on your daily experience?

Part F: Revealed travel preference evaluation

49) Do you prefer your trip numbers to be double?

50) Do you prefer your travel durations to be less than half?

51) Do you prefer your travel costs to be less than half?

52) Do you prefer to have more direct travel options?

53) Do you prefer your travel mode to be walking or cycling?

54) Do you prefer to choose alternative routes to your destination?

55) Do you prefer not to travel at morning and evening peak hours?

56) Do you prefer to have twice as more social/recreational/shopping trips than your work/school trips?

\section{Appendix 2. Origin-based time and cost impedance ratios}

\begin{tabular}{lll}
\hline Zones & Average & Decision \\
\hline 1 & -0.0012 & $*$ \\
2 & -0.0008 & \\
3 & -0.0008 & Negative \\
4 & 0.0005 & $*$ \\
5 & -0.0016 & $*$ \\
6 & -0.0016 & \\
7 & -0.0005 & $*$ \\
8 & -0.0016 & $*$ \\
9 & -0.0022 & $*$ \\
10 & -0.0014 & $*$ \\
11 & -0.0018 & $*$ \\
12 & -0.0002 & $*$ \\
13 & -0.0081 & \\
15 & -0.0022 & \\
\hline
\end{tabular}

*Significant impedance difference results, taken into DIX calculation. 


\section{Appendix 3. Simulation results}

\begin{tabular}{|c|c|c|c|c|c|}
\hline \multirow[t]{2}{*}{ Zones } & \multicolumn{2}{|l|}{ Trip policy indicators and ratio totals } & \multicolumn{2}{|l|}{ Added DIX impact* } & \multirow[t]{2}{*}{ General evaluation } \\
\hline & Work (w) & All other $(0)$ & Work (w) & All other $(0)$ & \\
\hline 1 & Access: 0.032, TravQual: 0.018 & Access: 0.033, TravQual: 0.016 & $0.05+0.67=0.72$ & $0.049+0.66=0.71$ & $\begin{array}{l}\mathrm{w}=\mathrm{o}^{*} \\
\text { Access is improved }\end{array}$ \\
\hline 2 & Access: 0.05 , TravQual: 0.021 & TravQual: 0.024 & $0.071+0.61=0.68$ & $0.024+0.69=0.71$ & $\begin{array}{l}\mathrm{W} \neq \mathrm{O}^{* *} \\
\text { Access is improved }\end{array}$ \\
\hline 3 & Access: 0.05, TravQual: 0.016, LandEnv: 0.042 & Access: 0.04, TravQual: 0.019 & $0.104+0.63=0.73$ & $0.059+0.65=0.71$ & $\begin{array}{l}\mathrm{w} \neq 0 \\
\text { Access \& LandEnv }\end{array}$ \\
\hline 4 & Access: 0.055, LandEnv: 0.043 & Access: 0.064 , TravQual: 0.014 & $0.098+0.61=0.71$ & $0.078+0.65=0.73$ & $\begin{array}{l}\mathrm{w} \neq 0 \\
\text { Access \& LandEnv }\end{array}$ \\
\hline 5 & Access: 0.048, TravQual: 0.018 & Access: 0.049 , TravQual: 0.018 & $0.067+0.63=0.7$ & $0.067+0.63=0.7$ & $\begin{array}{l}\mathrm{w}=\mathrm{o} \\
\text { Access is improved }\end{array}$ \\
\hline 6 & $\mathrm{~N} / \mathrm{A}$ & & & & \\
\hline 7 & Access: 0.026, TravQual: 0.027 & Access: 0.03 , TravQual: 0.026 & $0.053+0.69=0.75$ & $0.056+0.67=0.72$ & $\begin{array}{l}\mathrm{W} \sim 0^{* * *} \\
\text { TravQual is improved }\end{array}$ \\
\hline 8 & TravQual: 0.02 & TravQual: 0.022 & $0.022+0.63=0.65$ & $0.022+0.65=0.67$ & $\begin{array}{l}\mathrm{w}=\mathrm{o} \\
\text { TravQual is improved }\end{array}$ \\
\hline 9 & LandEnv: 0.037 & PhysBarr: 0.052 & $0.037+0.60=0.64$ & $0.052+0.68=0.73$ & $\begin{array}{l}\mathrm{W} \neq 0 \\
\text { LandEnv \& PhysBarr }\end{array}$ \\
\hline 10 & Access: 0.047 & Access: 0.035 , TravQual: 0.032 & $0.047+0.66=0.71$ & $0.067+0.66=0.72$ & $\begin{array}{l}\mathrm{W} \neq 0 \\
\text { Access \& TravQual }\end{array}$ \\
\hline 11 & PhysBarr: 0.049, TravQual: 0.011 & Access: 0.059 & $0.061+0.65=0.71$ & $0.059+0.65=0.71$ & $\begin{array}{l}\mathrm{W} \neq 0 \\
\text { PhysBarr\& Access }\end{array}$ \\
\hline 12 & Access: 0.039, LandEnv: 0.044, TravQual: 0.017 & Access: 0.037, TravQual: 0.02 & $0.1+0.62=0.72$ & $0.056+0.63=0.68$ & $\begin{array}{l}\mathrm{w} \neq 0 \\
\text { Access \& LandEnv }\end{array}$ \\
\hline 13 & Access: 0.066, TravQual: 0.022 & Access: 0.06 & $0.089+0.56=0.65$ & $0.06+0.58=0.64$ & $\begin{array}{l}\mathrm{w} \neq 0 \\
\text { Access is improved }\end{array}$ \\
\hline 14 & Access: 0.038 , TravQual: 0.015 & Access: 0.036 , TravQual: 0.015 & $0.053+0.63=0.69$ & $0.051+0.62=0.67$ & $\begin{array}{l}\mathrm{w}=\mathrm{o} \\
\text { Access is improved }\end{array}$ \\
\hline 15 & Access: 0.035 , TravQual: 0.02 & Access: 0.036 & $0.055+0.62=0.68$ & $0.036+0.53=0.57$ & $\begin{array}{l}\mathrm{w} \neq 0 \\
\text { Access is improved }\end{array}$ \\
\hline
\end{tabular}

${ }^{*} \mathrm{w}=\mathrm{o}$ means in that particular zone work and all other trips response to same policies.

** $\mathrm{W} / \mathrm{o}$ means in that particular zone work and all other trips do not response to same or similar policies.

${ }^{* * *} \mathrm{~W} \sim 0$ means in that particular zone work and all other trips response to similar policies.

\section{References}

Alver, Y., Mizokami, S., 2006. A combined RP/SP route choice study between expressways and ordinary roads by using route choice survey's data. Infrastruct. Plan. Rev. 23 (2), $521-532$

Banister, D., 2002. Transport Planning. E\&FN Spon, London.

Barceló, J., 2010. Models, traffic models, simulation, and traffic simulation. Springer, New York. Battellino, H., 2009. Transport for the transport disadvantaged: a review of service delivery models in New South Wales. Transp. Policy 16 (3), 123-129.

Blair, N., Hine, J., Bukhari, S., 2013. Analysing the impact of network change on transport disadvantage: a GIS-based case study of Belfast. J. Transp. Geogr. 31 (1), 192-200.

Bunker, J., Kashfi, S., Yigitcanlar, T., 2015. Understanding the effects of complex seasonality on suburban daily transit ridership. J. Transp. Geogr. 46 (1), 67-80.

Cervero, R., 2003. Are induced travel studies inducing bad investments? Access 22 (1), 22-27.

Church, A., Frost, M., Sullivan, K., 2000. Transport and social exclusion in London. Transp. Policy 7 (3), 195-205.

Currie, G., Richardson, T., Smyth, P., Vella-Brodrick, D., Hine, J., Lucas, K., Stanley, J., 2009. Investigating links between transport disadvantage, social exclusion and well-being in Melbourne: preliminary results. Transp. Policy 16 (3), 97-105.

Currie, G., Richardson, T., Smyth, P., Vella-Brodrick, D., Hine, J., Lucas, K., Stanley, J., 2010. Investigating links between transport disadvantage, social exclusion and well-being in Melbourne: updated results. Res. Transp. Econ. 29 (1), 287-295.

Delbosc, A., Currie, G., 2010. Modelling the social and psychological impacts of transport disadvantage. Transportation 18 (1), 31-41.

Delbosc, A., Currie, G., 2011a. Transport problems that matter: social and psychological links to transport disadvantage. J. Transp. Geogr. 19 (1), 170-178.

Delbosc, A., Currie, G., 2011b. The spatial context of transport disadvantage, social exclusion and well-being. J. Transp. Geogr. 19 (6), 1130-1137.

Delbosc, A., Currie, G., 2011c. Exploring the relative influences of transport disadvantage and social exclusion on well-being. Transp. Policy 18 (4), 555-562.

Diana, M., 2004. Innovative systems for the transportation disadvantaged: toward more efficient and operationally usable planning tools. Transp. Plan. Technol. 27 (4), 315-331.

Dodson, J., Burke, M., Evans, R., Gleeson, B., Sipe, N., 2010. Travel behavior patterns of different socially disadvantaged groups. Transp. Res. Rec. 2163 (1), 24-31.

Duvarci, Y., Mizokami, S., 2007. What if the suppressed travel demands of the transport disadvantaged were released: results of a simulation approach. J. Eastern. Asia. Soc Transp. Stud. 7 (1), 1433-1445.

Duvarci, Y., Mizokami, S., 2009. A suppressed demand analysis method of the transportation disadvantaged in policy making. Transp. Plan. Technol. 32 (2), 187-214.
Duvarci, Y., Yigitcanlar, T., 2007. Integrated modeling approach for the transportation disadvantaged. J. Urban Plann. Dev. 133 (3), 188-200.

Duvarci, Y., Yigitcanlar, T., Alver, Y., Mizokami, S., 2011. The variant concept of transportation disadvantaged: evidence from Aydin, Turkey and Yamaga, Japan. J. Urban Plann. Dev. 137 (1), 82-90.

Engels, B., Liu, G., 2011. Social exclusion, location and transport disadvantage amongst non-driving seniors in a Melbourne municipality, Australia. J. Transp. Geogr. 19 (4) 984-996.

Ewing, R., DeAnna, M., Li, S., 1996. Land use impacts on trip generation rates. Transp. Res. Rec. 1518 (1), 1-6.

Hine, J., Grieco, M., 2003. Scatters and clusters in time and space: implications for delivering integrated and inclusive transport. Transp. J. 10 (1), 299-306.

Hine, J., Mitchell, F., 2003. Transport Disadvantage and Social Exclusion. Ashgate, London.

Jones, P., 2011. Developing and applying interactive visual tools to enhance stakeholder engagement in accessibility planning for mobility disadvantaged groups. Res. Transp. Bus. Manag. 2 (1), 29-41.

Jones, P., Lucas, K., 2012. The social consequences of transport decision-making: clarifying concepts, synthesising knowledge and assessing implications. J. Transp. Geogr. 21 (1) $4-16$.

Kamruzzaman, M., Hine, J., 2011. Participation index: a measure to identify rural transport disadvantage? J. Transp. Geogr. 19 (4), 882-899.

Kamruzzaman, M., Hine, J., 2012. Analysis of rural activity spaces and transport disadvantage using a multi-method approach. Transp. Policy 19 (1), 105-120.

Kamruzzaman, M., Yigitcanlar, T., Washington, S., Currie, G., 2014. Australian baby boomers switched to more environmentally friendly modes of transport during the global financial crisis. Int. J. Environ. Sci. Technol. 11 (8), 2133-2144.

Kamruzzaman, M., Hine, J., Yigitcanlar, T., 2015. Investigating the link between carbon dioxide emissions and transport related social exclusion in rural Northern Ireland. Int. J. Environ. Sci. Technol. http://dx.doi.org/10.1007/s13762-015-0771-8.

Lam, S., Xie, F., 2002. Transit path-choice models that use revealed preference and stated preference data. Transp. Res. Board 1799 (1), 58-65.

Licaj, I., Haddak, M., Pochet, P., Chiron, M., 2012. Individual and contextual socioeconomic disadvantages and car driving between 16 and 24 years of age. J. Transp. Geogr. 22 (1), 19-27.

Litman, T., 1997. Evaluating Transportation Equity. Victoria Transport Policy Institute Victoria, Canada.

Loader, C., Stanley, J., 2009. Growing bus patronage and addressing transport disadvantage: the Melbourne experience. Transp. Policy 16 (3), 106-114.

Lucas, K., 2006. Providing transport for social inclusion within framework for environmental justice in UK. Transp. Res. A 40 (1), 801-809. 
Lucas, K., 2011. Making the connections between transport disadvantage and the socia exclusion of low-income populations in the Tshwane Region of South Africa. J. Transp. Geogr. 19 (6), 1320-1334.

Lucas, K., 2012. Transport and social exclusion: where are we now? Transp. Policy 20 (1) 105-113.

McGrail, M., Humphreys, J., 2009. Measuring spatial accessibility to primary care in rura areas: improving the effectiveness of the two-step floating catchment area method. Appl. Geogr. 29 (4), 533-541.

Metz, D., 2003. Transport policy for an ageing population. Transp. Rev. 23 (4), 375-386.

Mokhtarian, P., Salomon, I., Handy, S., 2006. The impacts of ICT on leisure activities and travel: a conceptual exploration. Transportation 33 (1), 263-289.

Nicolle, C., Peters, B., 1999. Elderly and disabled travellers: intelligent transportation systems designed for the third millennium. Trans. Hum. Factors 1 (2), 121-134.

Parumog, G., Kakimoto, R., Mizokami, S., 2008. Task complexity in multi-attribute stated choice environmental evaluation. J. Eastern. Asia. Soc. Transp. Stud. 7 (1), 94-104.

Power, A., 2012. Social inequality, disadvantaged neighbourhoods and transport deprivation: an assessment of the historical influence of housing policies. J. Transp. Geogr. 21 (1) 39-48.

Rashid, K., Yigitcanlar, T., 2015. A methodological exploration to determine transportation disadvantage variables: the partial least square approach. World Rev. Intermodal Transp. Res. 5 (3), 221-239.

Rau, H., Vega, A., 2012. Spatial (Im) mobility and accessibility in Ireland: implications for transport policy. Growth Chang. 43 (4), 667-696.
Schlossberg, M., 2004. Coordination as a strategy for serving the transportation disadvantaged a comparative framework of local and state roles. Public Works Manag. Policy 9 (2), 132-144

Schwanen, T., Lucas, K., Akyelken, N., Solsona, D., Carrasco, J., Neutens, T., 2015. Rethinking the links between social exclusion and transport disadvantage through the lens of social capital. Transp. Res. A 74 (1), 123-135.

Stanley, J., Vella-Brodrick, D., 2009. The usefulness of social exclusion to inform social policy in transport. Transp. Policy 16 (3), 90-96.

Thompson, G., 2001. New insights into the value of transit: modeling inferences from Dade County. Transp. Res. Rec. 1753 (1), 52-58.

Vergel, K., Tiglao, N., 2005. Assessment of integrated environmental strategies for Metro Manila. J. Eastern. Asia. Soc. Transp. Stud. 6 (1), 3105-3120.

Wasfi, R., Levinson, D., El-Geneidy, A., 2012. Measuring the transportation needs of seniors. J. Transp. Lit. 6 (2), 8-32.

Yigitcanlar, T., Kamruzzaman, M. 2014. Investigating the interplay between transport, land use and the environment: a review of the literature. Int. J. Environ. Sci. Technol. 11 (8), 2121-2132.

Yigitcanlar, T., Sipe, N., Evans, R., Pitot, M., 2007. A GIS-based land use and public transport accessibility indexing model. Aust. Plann. 44 (3), 30-37.

Yigitcanlar, T., Rashid, K., Dur, F., 2010. Sustainable urban and transport development for transportation disadvantaged: a review. Open Transp. J. 4 (1), 1-8. 